\title{
Factors influencing the habitat choice of pangolins (Manis spp.) in low land of Nepal
}

\author{
Arati Shrestha $^{1}$ (D) | Santosh Bhattarai ${ }^{2}$ (D) | Binod Shrestha ${ }^{2}$ (D) | \\ Narayan Prasad Koju ${ }^{3,4}$
}

${ }^{1}$ Central Department of Environmental Science, Tribhuvan University, Kathmandu, Nepal

${ }^{2}$ National Trust for Nature ConservationBiodiversity Conservation Center, Chitwan, Nepal

${ }^{3}$ Natural Resources Management Program, Centre for Post Graduate Studies, Nepal Engineering College, Lalitpur, Nepal

${ }^{4}$ Department of Psychology, University of Washington, Seattle, WA, USA

\section{Correspondence}

Narayan Prasad Koju, Natural Resources Management Program, Centre for Post

Graduate Studies, Nepal Engineering

College, Lalitpur, Nepal.

Email: npkoju.2003@gmail.com

Funding information

The study was supported by the National Trust for Nature Conservation-Biodiversity Conservation Centre (NTNC-BCC) through USAID Hariyo Ban Program as MSc Thesis Research Grant to Arati Shrestha.

\begin{abstract}
Pangolins in the genus Manis are nocturnal, burrowing, insectivorous mammals listed as Critically Endangered or Endangered by the International Union for Conservation of Nature. Two species of pangolins are found in Nepal: the Chinese pangolin (Manis pentadactyla) and Indian pangolin (Manis crassicaudata). Despite having high conservation priority, little attention has been given to conservation interventions of both species of pangolins found in the Terai region (low land) of Nepal. The present study assesses habitat use and factors affecting the habitat choice of pangolins in low land (Terai), Nepal, focusing on Amritdharapani Community Forest of Chitwan district. Pangolin burrows were used as the indirect signs, and opportunistic sampling method was used to record the burrows. After the identification of all occurrence sites (burrows) in the field, random points were generated excluding the points where burrows were recorded for sampling of nonoccurrence sites. A total of thirty-nine burrows were observed at elevations ranging from 301 to 413 masl. Burrows were frequently associated with northwest aspects, gentle slope $\left(15^{\circ}-20^{\circ}\right)$, moderate canopy cover (51\%-75\%), red-colored soil, and acidic soils with $\mathrm{pH} 6.5-7$. The burrows were most common in areas with weak human disturbance (i.e., 1,500-1,700 $\mathrm{m}$ from settlements), 800-1,200 m from roads, and within $300 \mathrm{~m}$ from a water source and within $20 \mathrm{~m}$ from the nearest termitarium. Distance to settlement, distance to road, soil pH, and canopy cover were found to affect the habitat choice of pangolins in the study area.
\end{abstract}

\section{KEYWORDS}

burrow, habitat preferences, occurrence sites, PCA

\section{1 | INTRODUCTION}

Pangolins (family: Manidae) encompass eight extant species distributed discontinuously through tropical and subtropical Asia and Africa (Marler, 2016). Nepal lies in the transition zone between
Palearctic and Oriental regions and hence is endowed with fauna characteristic of both regions, including the "Critically Endangered" Chinese pangolin (Manis pentadactyla) (Challender et al., 2019) and the "Endangered" Indian pangolin (Manis crassicaudata) (Baral \& Shah, 2008; Jnawali et al., 2011; Kaspal, 2009; Mahmood, Akrim,

This is an open access article under the terms of the Creative Commons Attribution License, which permits use, distribution and reproduction in any medium, provided the original work is properly cited.

(C) 2021 The Authors. Ecology and Evolution published by John Wiley \& Sons Ltd. 
et al., 2019; Mahmood, Challender et al., 2019). Both species have been upgraded to Appendix I of the Convention on International Trade in Endangered Species of Wild Fauna and Flora (CITES) due to the high threat of extinction (CITES, 2016), and both species have been accorded the highest degree of protection under the National Parks and Wildlife Conservation Act (NPWCA, 1973).

Pangolins have been reported throughout Nepal from Terai (lowland plain areas) to mid-hill regions rising up to $3,000 \mathrm{~m}$ above sea level particularly in eastern Nepal and have occupied an array of natural and man-made habitats including primary and secondary forests in both protected and nonprotected areas (Gurung, 1996; Sharma et al., 2020). They have been detected in open lands, riverine forests, sal (Shorea robusta) forest, mixed hardwood forests, bamboo forests, grasslands, and agricultural and degraded marginal lands near human settlements where there is availability of food, water, and sunlight (DNPWC \& DoF, 2018; Jnawali et al., 2011; Suwal, 2011). A national pangolin survey carried out in 2016 revealed the distribution of pangolins in 43 districts of Nepal. The Chinese pangolin and Indian pangolin were distributed in 25 and 7 districts, respectively (DNPWC \& DoF, 2018). Chinese pangolins were more widely distributed, occurring up to $2000 \mathrm{~m}$ in Nepal's central and eastern regions. Indian pangolins occurred only in a small part of southern Nepal, the eastern foothills, and the Terai region, mostly in tropical and subtropical forests and mostly below $500 \mathrm{~m}$, although recently recorded at an elevation of 675 masl (Baral \& Shah, 2008; DNPWC \& DoF, 2018; Jnawali et al., 2011; Suwal et al., 2020). Baral and Shah (2008) has discussed the distribution of Chinese pangolins with upper altitudinal gradients of $2,500 \mathrm{~m}$. The occurrence of pangolin is greatly influenced by various habitat covariates such as canopy coverage, soil type, aspect, and ground vegetation coverage, distance to water source, human settlements, agricultural land, and anthropogenic factors such as poaching as well (Bhandari \& Chalise, 2014; Gurung, 1996; Katuwal et al., 2017; Sharma et al., 2020; Suwal et al., 2020).

Pangolin habitat use, and characteristics of used or associated habitats appear to differ according to environmental conditions (Karawita et al., 2018), and identification of suitable habitat and potential distribution is essential for developing conservation strategies for these species (Katuwal et al., 2017). The current study assessed pangolin habitat preferences to aid in preventing the loss of prime pangolin habitats in Amritdharapani Community Forest of Chitwan District, Nepal.

\section{2 | METHODOLOGY}

\section{1 | Study area}

The Chitwan District is located at low land (Terai) in the Bagmati Province of Nepal at $83^{\circ} 55^{\prime} 45^{\prime \prime}$ to $84^{\circ} 48^{\prime} 15^{\prime \prime}$ East longitudes and $27^{\circ} 52^{\prime} 6^{\prime \prime}$ to $27^{\circ} 46^{\prime}$ North latitude, an area of tropical and subtropical monsoon climate with high humidity (Poudel, 2014). Chitwan is famous for Chitwan National Park, a protected area listed as a UNESCO world heritage site. Evidence of the occurrence of both the Chinese pangolin and the Indian pangolin was recorded from the Chitwan District (DNPWC \& DoF, 2018; Kaspal, 2009; Suwal et al., 2020). The study was carried out in Amritdharapani Community Forest located in Rapti Municipality of Chitwan District (Figure 1). It extends from $27^{\circ} 38^{\prime} 20^{\prime \prime} \mathrm{N}$ to $27^{\circ} 41^{\prime} 43^{\prime \prime} \mathrm{N}$ latitude and $84^{\circ} 35^{\prime} 47^{\prime \prime} \mathrm{E}$ to $84^{\circ} 37^{\prime} 52^{\prime \prime} \mathrm{E}$ longitude and covers an area of 853.182 hectares. This forest was comprised of the typical character of the Terai region of Nepal: mixed vegetation of different tree species dominated by Shorea robusta, Lagerstroemia parvifolia, Careya arborea, Syzygium operculatum, Rhus wallichii, Eugenia jambolana, etc. Many wildlife species such as Panthera pardus, Manis pentadactyla, Axis, axis, Herpestus edwardsi, Sciuridae sp., Macaca mulata, etc., are also found in this community forest.

\section{2 | Methods}

The distribution of pangolins was determined through field surveys between February and April 2019. Each survey was conducted in two phases. Initially, the whole community forest was thoroughly searched by walking along different available trails by a team of at least four people to explore the pangolin signs. Two wildlife technicians and forest guide having knowledge about pangolin signs and potential areas of burrow distribution were also in the team for exploration and confirmation. Opportunistic sampling was then used to collect information related to pangolin burrows. The pangolins are highly elusive and nocturnal animals, notably difficult to observe in the wild (Kaspal, 2009). Therefore, its presence in the study area was inferred based on indirect signs such as burrows, footprints, tracks, and fecal matter (Akrim et al., 2017; Mahmood et al., 2017; Karawita et al., 2018; Waseem et al., 2020). Burrows were classified as "old" or "new" following Suwal (2011). Burrows with compact and dry soil with dry leaves and lacking signs such as fresh scratches, footprints, and fecal pellets were classified as old burrows, while burrows with loose soil without dry leaves around it, having signs of fresh scratches, footprints, and fecal pellets, are classified as new burrows. The occurrence sites, that is, sites having burrows, were identified in the field by an intensive survey of the study area. Once these sites were identified, 39 random points were generated in ArcGIS 10.3 (excluding the points where burrows were recorded in the initial survey) for sampling of nonoccurrence sites (sample points without burrows). All of them were visited for sampling where no sign of burrow was recorded and listed as nonoccurrence sites.

In each of the occurrence and nonoccurrence sites selected for sampling, habitat covariates were recorded including elevation, slope, aspect, soil pH, soil type based on color, canopy cover (\%) above the burrow, distance to the nearest water source, and distance to nearest termitarium. Besides, distance to the nearest settlement and distance to the nearest road were also recorded, to index anthropogenic effects on the occurrence of pangolins (DNPWC \& DoF, 2018; 
FIGURE 1 Map showing the location of the study area

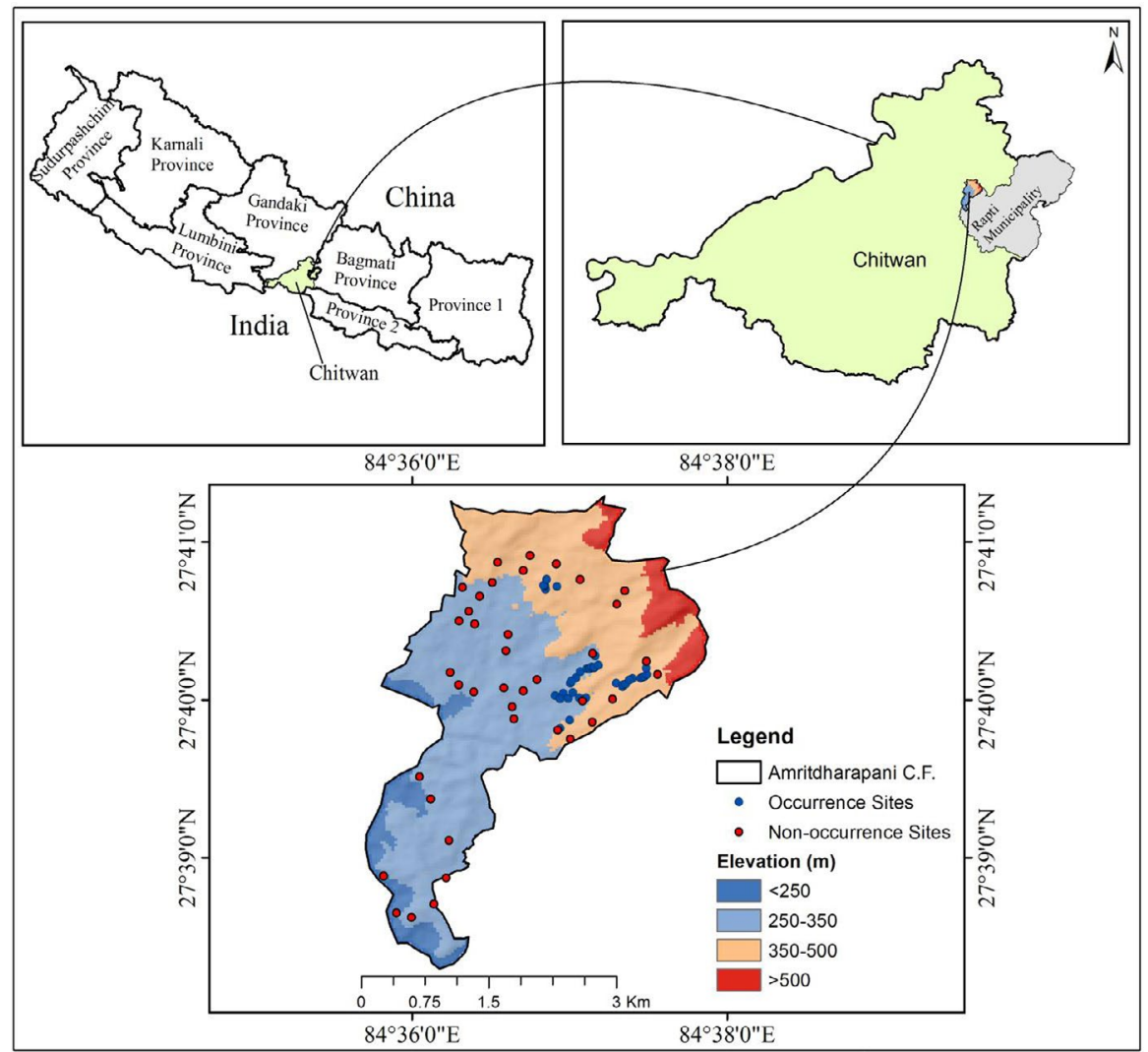

Katuwal et al., 2017; Sharma et al., 2020). In each occurrence site, the geographical coordinates of the burrow location were recorded using a GPS receiver (Garmin eTrex 10). Vegetative canopy cover was determined using a spherical densiometer (Lemmon, 1956). The soil sample was collected, and soil $\mathrm{pH}$ was determined later in the laboratory by using a $\mathrm{pH}$ meter. The slope at the center of each site was measured using a clinometer. Burrow location and random point generated within GIS were considered as the site center for the occurrence and nonoccurrence site, respectively. Covariates such as distance to the nearest settlement, road, and water body were based on GPS coordinates retrieved using ArcGIS 10.3.

\section{3 | Statistical analysis}

R software version 3.5.1 was used for all statistical analyses. As the data were sufficiently normally distributed and the sample size was greater than $30, z$ tests were carried out to test the hypothesis that pangolin occurrence sites differed in habitat make-up from nonoccurrence sites by comparing the difference in mean for each habitat variable. Principal component analysis (PCA) was used to quantitatively and qualitatively describe pangolin occurrence and nonoccurrence sites concerning the variance in measured habitat variables, and to understand how these sites diverge from each other (Shenoy et al., 2006). The PCA was based on a correlation matrix, which can be preferable to a covariance matrix when the focal variables have different units (Jackson, 1991). The variables that were entered into PCA were elevation $(\mathrm{m})$, slope $\left(^{\circ}\right)$, soil $\mathrm{pH}$, canopy coverage (\%), distance to the water source $(m)$, distance to nearest termitarium (m), distance to settlement $(\mathrm{m})$, and distance to the road $(\mathrm{m})$.

\section{3 | RESULTS}

A total of 39 burrows were recorded from Amritdharapani Community Forest, out of which $35.89 \%(n=14)$ were old burrows, while $64.10 \%$ ( $n=25$ ) were new burrows.

Pangolin burrows were distributed within an elevation range of 300-413 masl, and $30.77 \%$ of total burrows occurred within 320340 masl. Burrows was not recorded below an elevation of 300 masl, and the distribution of the burrow was related significantly with elevation ( $p=.0015)$. Pangolin burrows were distributed on slopes of $5^{\circ}-22^{\circ}$, and $56.41 \%$ of total burrows occurred on slopes of $15^{\circ}-20^{\circ}$. No burrows were recorded on slopes less than $5^{\circ}$ or greater than $25^{\circ}$, and burrow occurrence was related significantly to slope $(p=.0001)$. $56.41 \%$ of burrows were recorded on slopes with northwest aspect, and burrows were not recorded on slopes facing east. $74.36 \%$ burrows were recorded in areas having canopy cover between $51 \%$ and $75 \%$, while no burrows were recorded in areas where canopy cover was between $0 \%$ and $50 \%$. Similarly, $56.41 \%$ burrows were recorded in red-colored soil, followed by brown-colored soil (33.33\%), and $2.56 \%$ of burrows were recorded in reddish-brown, blackish-brown, and yellow soil. $58.97 \%$ of burrows were recorded in neutral soil $(\mathrm{pH}$ 6.5-7), $30.77 \%$ in slightly acidic soil (pH 6-6.5), and only $5.13 \%$ in alkaline soil $(\mathrm{pH}>7)$. Canopy cover and soil $\mathrm{pH}$ showed a significant relation to burrow distribution $(p<.05)$. 
Furthermore, the burrows were recorded within 40-800 m from the nearest water source, with $25.64 \%$ of burrows distributed within 200-300 m from the water source, and only $2.56 \%$ at a distance of $700-800 \mathrm{~m}$ from the water source. No burrows were recorded beyond $800 \mathrm{~m}$ from a water source. The number of burrows decreased with increasing distance from the nearest water source $(p=.003)$. Pangolin burrows were recorded within a range of 700-1900 m from the nearest human settlement, and $30.77 \%$ of them were recorded at $1,500-1,700 \mathrm{~m}$ from a settlement. Only $7.69 \%$ of the burrows were recorded at 700-900 $\mathrm{m}$ from the nearest human settlement, and there was no significant relationship $(p>.05)$ between distance to settlement and burrow distribution.

Similarly, burrows were observed between 600 and $1,800 \mathrm{~m}$ from the nearest road, and $23.08 \%$ recorded at 800 to $1,200 \mathrm{~m}$ from the nearest road. Only $10.26 \%$ of burrows were observed relatively close to $(600-800 \mathrm{~m})$ or far from (1,600-1,800 m) the nearest road, and there was no significant relationship $(p>.05)$ between distance to the nearest road and burrow distribution.

Burrows were found within $0-140 \mathrm{~m}$ of the nearest termitarium (food source). $43.6 \%$ burrows were observed within $20 \mathrm{~m}$ of the nearest termitarium, and only $2.6 \%$ were recorded at distances greater than $120 \mathrm{~m}$ from the nearest termitarium. There was a significant relationship between distance to nearest termitarium and burrow distribution ( $p=.0007$ ).

Using PCA, the first four principal components together explained $86.72 \%$ of the variation in the data (Table 1). PC5 (7.49\%) and the other three principal components were excluded from the model for the sake of simplicity. The first principal component explained $33.42 \%$ of the variance (Table 1 ) and was positively influenced by distance to road and distance to settlement, while the second principal component explained $28.47 \%$ of the variance and was positively influenced by soil $\mathrm{pH}$ and canopy cover (Table 1). Most of the occurrence sites clustered in the first and second quadrants, whereas the nonoccurrence sites clustered in the third and fourth quadrants. Distance to the road, distance to settlement, soil $\mathrm{pH}$, and canopy cover had large impacts on the distribution of data (Figure 2). Distance to food source was negatively correlated with canopy cover, soil pH, elevation, and slope.

\section{4 | DISCUSSION}

Suwal et al. (2020) predicted the elevation range of the pangolin habitat to lie between 132 and 2,704 masl and classified the habitat below 500 masl and above 1,750 masl as less suitable for the taxon. Our study revealed that burrows were most common from 300 to 350 masl in the study area and distributions of burrows are significant to elevation. Gathorne-Hardy et al. (2001) explained that the abundance of termite mounds decreases with increased elevation. Burrows were sparsely distributed above 400 masl. Bhandari and Chalise (2014) and Katuwal et al. (2013) suggested pangolins might prefer tropical and subtropical climatic zones. Lamichhane and Pokhrel (2019) recorded maximum burrows at 500-600 mas and found a decrease in burrow numbers with an increase in elevation above 600 masl. The study carried out by Dorji et al. (2020) also supported a negative relationship between elevation and number of burrows.

Pangolins mostly prefer slopes less than $50^{\circ}$ (Wu et al., 2003), and in this study, most burrows were recorded on slopes between $15^{\circ}$ and $20^{\circ}$ showing significant relation to slope. Our result is similar to the findings of Karawita et al. (2018) and Sharma et al. (2020), which showed the preference of less than $30^{\circ}$ slope and $15^{\circ}-22^{\circ}$ slope, respectively, by the taxon. The preference of slope less than $25^{\circ}$ by the species might be for the easy movement in the area and for avoidance of terrain slope (Acharya et al., 2021). Slopes in this range may facilitate digging (Dorji, 2016) and reduce rain-mediated soil erosion. Maurice et al. (2019) also recorded more burrows in gentle and steep slopes but very few in very steep slopes. But this result contradicts the findings of studies by Wu et al. (2004) and Suwal et al. (2020), which report pangolin preference for slopes of $30-60^{\circ}$ and $30-50^{\circ}$, respectively, for making burrows. Burrows were not recorded in flat areas. Our results also showed the strong correspondence between elevation and slope as depicted in the PCA plot. In the study area, it was observed that with the increase in elevation, the slope also increased. Thus, it supported the findings of less burrows with increase in both elevation and slope.

Although aspect was not a statistically significant predictor of burrow location in our study, most of the burrows encountered

\begin{tabular}{|lcccc}
\hline Variables & PC1 & PC2 & PC3 & PC4 \\
\hline Elevation & 0.97 & 0.88 & -0.93 & 0.33 \\
\hline Slope & 0.74 & 0.67 & -0.01 & -1.42 \\
\hline Soil pH & 0.46 & 1.42 & 0.41 & 0.12 \\
\hline Canopy cover & 0.24 & 1.34 & 0.12 & 0.59 \\
\hline Water source distance & 0.89 & -1.16 & 0.69 & 0.19 \\
\hline Settlement distance & 1.69 & -0.35 & -0.13 & 0.09 \\
\hline Road distance & 1.66 & -0.51 & -0.09 & 0.11 \\
\hline Nearest termitarium distance & -0.31 & -0.55 & -1.44 & -0.0 .04 \\
\hline Eigenvalues & 2.67 & 2.28 & 1.17 & 0.82 \\
\hline Total variances explained & $33.42 \%$ & $28.47 \%$ & $14.63 \%$ & $10.20 \%$ \\
\hline
\end{tabular}

TABLE 1 Character loading, eigenvalue, and percent variance explained by the first four principal components

Note: The bold number represents for loading factors of a variable over 1. 


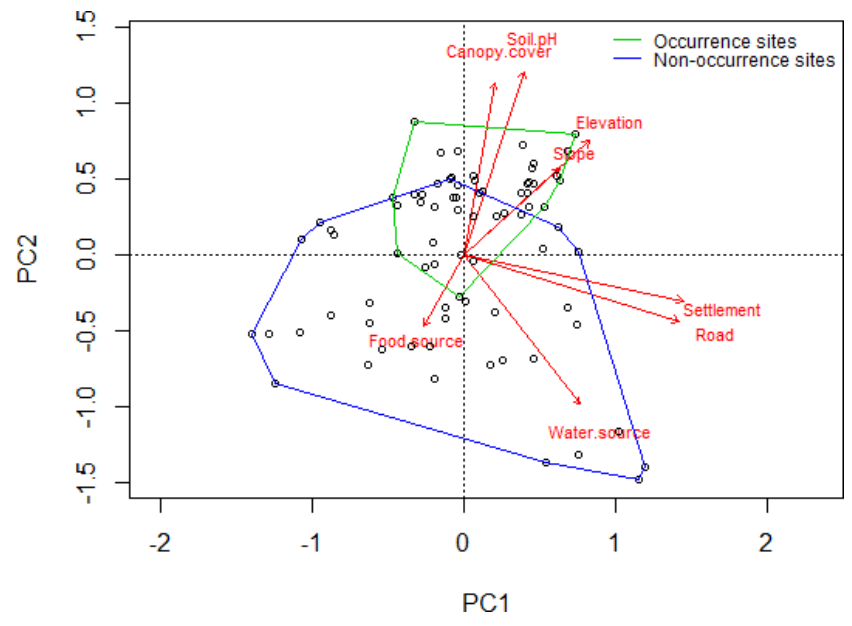

FIGURE 2 PCA plot showing factors affecting the distribution of burrows

were on slopes with northwest and southwest aspects, in general agreement with several other studies. Bhandari and Chalise (2014) reported similar patterns in Nagarjun Forest of Shivapuri National Park. Dhakal (2016) also reported the pangolin's preference to north-facing slopes. The pangolin prefers the west slope probably for getting sunlight before foraging (Acharya et al., 2021). However, Suwal (2011) reported the random distribution of burrows in different aspects. Thapa et al. (2014) also observed preference of southwest aspect by pangolins for digging burrows. Gurung (1996) recorded pangolin preference for south-facing slopes. A study by Dhital et al. (2020) in the Nagarjun forest of Shivapuri National Park showed pangolin preference for eastern aspects. The openings of pangolin burrows often face the sun (eastward) to make digging easier and to maintain burrow temperature in winter (Wu et al., 2004). The preference for certain aspects in certain locations might be influenced by local climatic conditions, available food, water, and degree of human interference (Dhakal, 2016).

Burrows were mostly found in areas having canopy cover between $51 \%$ and $75 \%$, which is similar to another study by Rai et al. (2019) and Suwal et al. (2020) in Nepal, who reported that pangolins prefer habitats with medium canopy coverage rather than forests that are too dense or too sparse. The distribution of burrows was found to be significant with canopy cover. Other studies carried out in districts located in the mid-hills of Nepal (Bhandari \& Chalise, 2014; Dhakal, 2016; Dhital et al., 2020) have shown pangolin preference for burrowing under low canopy cover (25\%-50\%), which contradicted this study. Thapa et al. (2014) in a study of the Taplejung District recorded more burrows associated with a canopy cover of $0 \%-25 \%$ and the lowest number of burrows under canopy cover of $50 \%-75 \%$. The variation observed may be due to the location of the study areas in different geographical locations. Bhandari and Chalise (2014) also found that the lowest burrow numbers occurred in areas having more than $75 \%$ canopy cover, which corroborated our study. Wu et al. (2003) in a winter study of Dawuling Natural Reserve recorded that pangolins avoid vegetation density over $75 \%$ and fewer than $30 \%$. Karawita et al. (2018) found burrows were more frequent in areas with moderate canopy cover (41\%-70\%). In places where pangolins prefer low canopy cover sites, they might be influenced by prey availability because pangolin's prey; that is, termites occur more in dry areas than in wet areas. The dense forest canopy helps in the protection of forest moisture, and it also determines the density of the understory (Maurice et al., 2019).

Most of the burrows were observed in red-colored soil, which corresponded to findings of the other studies (Acharya, 2001; Sharma et al., 2020) Sharma et al. (2020) suggested more occurrences of pangolin burrows in red soil as a result of increased food availability compared with brown soils. But the observation contradicts the findings of Kaspal (2009), Suwal (2011), and Suwal et al. (2020), which showed the preference for brown-colored soil for digging burrows. Kaspal (2009) found the burrows with more depth and diameter in red-colored soil than in brown-colored soil.

The majority of burrows (56.41\%) were found in soils having acidic or neutral $\mathrm{pH}$. The distribution of burrows showed a significant relationship with soil pH. Rai et al. (2019) also recorded more burrows in soil having acidic and more or less neutral $\mathrm{pH}$ value. The presence of more burrows in acidic soil might be supported by the fact that its prey termites are mostly found in acidic and weakly alkaline soils with $\mathrm{pH}$ values between 3.5 and 8.7 and increase in soil $\mathrm{pH}$ might lead to termite inactivation (Li et al., 2017). This is supported by the dominance of red-colored soil in sites where burrows were observed. Red-colored soil is comparatively more acidic than browncolored soil. Soil $\mathrm{pH}$ helps to determine what type of vegetation will be available in the area, and indeed, canopy cover corresponded to soil $\mathrm{pH}$. Termite abundance tends to decrease in abundance in acidic soil conditions.

The gradual decreases in the number of burrows were observed with the increase in distance to water source showing significant relation between burrow distribution and distance to a water source, which is similar to the findings of Dorji et al. (2020). From this, it can be presumed that the distance to the water source acts as one of the factors affecting the distribution of pangolins. Katuwal et al. (2013) recorded a higher number of burrows in an area within a distance of $100 \mathrm{~m}$ from the water source and observed only one burrow at 700-m distance from the water source. Katuwal et al. (2017) recorded more pangolin occurrence in area within 200 m distance from water source. Karawita et al. (2018) found burrows were more frequent in areas with distance 100$200 \mathrm{~m}$ from the water source. The presence of burrows at the proximity of the water source might be for avoiding predators and conserving vital energy while walking a long distance for water (Bista et al., 2017). As the pangolins need water for themselves and ants, termites, and other insects also prefer moist habitats, this might be another reason behind the presence of burrows near a water source (Katuwal et al., 2013).

The number of burrows increased with the increase in distance from settlement area and road. This finding has been supported by other studies carried out in Nepal. Katuwal et al. (2017) recorded more pangolin occurrence in the area with less disturbance (typically $>1,000 \mathrm{~m}$ from human settlements and road). In contrast to 
this, Sharma et al. (2020) recorded 51\% of occurrence plots within a 1000-m distance from settlement areas. Similarly, a study by Karawita et al. (2018) revealed burrow distribution was greater in an area with greater human disturbance $(<200 \mathrm{~m})$ and has decreased with increased distance from human settlement. Katuwal et al. (2013) recorded more burrows close to the settlement area with a distance of at least 50-200 m. Wu et al. (2003) observed pangolins dug burrows away from human habitation, which suggests an inclination to avoid disturbances. The study carried out by Gurung (1996) shows that human encroachment in the preferred habitats of the pangolin is the reason behind the decline of species in Nepal. Areas close to settlements experience more frequent livestock and human activity, and pangolins have been observed to leave their burrows following such activities (Katuwal et al., 2017). The collection of fallen logs by humans and excessive trampling by larger-hoofed cattle result in detrimental effects on the survival of pangolins due to disturbance and decrease in prey availability. Apart from that, foot trails and settlements can ease the poaching of the species (Katuwal et al., 2017). Katuwal et al. (2013) observed burrows close to the small walking trails of the humans with more recorded within the distance of 0-50 m.

The gradual decreases in the number of burrows were observed with the increase in distance from the nearest termitarium showing significant relation between burrow distribution and distance to the nearest termitarium. This indicates the distance to the nearest food source has a significant impact on the distribution of burrows. The result can be supported by the fact that pangolins are specialist species with food specialization, that is, only eating ants and termites, and for the pangolins to thrive, there should be a natural abundance of its prey species, and hence, their habitat location is also linked with their prey species (Maurice et al., 2019; Wu et al., 2004). The burrows are also dug near the food source for the easy availability of prey during the winter months (Heath \& Vanderlip, 1988). The high termite species abundance and richness favor pangolin occurrence (Swart et al., 1999). In the study area, dead fallen logs and leaf litter were observed during field visits, which provide favorable habitats for ants and termites.

The studies on habitat preferences of the pangolin within the country and across its range countries have also reported variable findings (Bhandari \& Chalise, 2014; Katuwal et al., 2017; Lamichhane \& Pokhrel, 2019; Sharma et al., 2020; Suwal et al., 2020), which is supported by our result too. The study area is located in the low land of Nepal not having a slope greater than $40^{\circ}$ and elevation range below 600 masl, and the difference in climate and topography might have resulted in the variation in the habitat preference by the species compared with the other studies that were carried in mid-hill region of Nepal.

Our results supported the hypothesis that occurrence sites were significantly different from nonoccurrence sites in several of the variables we measured. Out of the eight variables used, distance to settlement, distance to road, soil $\mathrm{pH}$, and canopy coverage were the most significant factors responsible for burrow distribution in the study area. However, Katuwal et al. (2013) observed no marked effect of distance to settlement and road in the distribution of burrows. Suwal et al. (2020) reported elevation as the major influential variable in determining suitable habitat for pangolins. Aryal and Poudel (2018) reported that the elevation, canopy coverage, and presence of Schima wallichii as dominant species are the major habitat variables affecting the distribution of the burrows in their study at Nagarjun and Ranibari forests, Kathmandu. The main factors determining the presence and habitat choice of pangolins are the availability of prey and water, but it is found to vary depending on the species (Maurice et al., 2019). Similarly, some degree of uncertainty was observed on the major and most favorable ecosystem preferred by pangolins (Kingdon et al., 2013). Detections of pangolins close to the settlement area suggest that anthropogenic activities may play a major role in their survival (Katuwal et al., 2017). Proximity to human settlements has proved to be detrimental for pangolins as hunters often capture pangolins near their burrows (Zhang et al., 2017). According to Katuwal et al. (2017), canopy coverage and water sources played a positive role in determining the occurrence of pangolin. In the closed-canopy forest, prey species are highly abundant and there is less chance of erosion (Katuwal et al., 2017). According to Mahmood et al. (2014) and Pabasara et al. (2015), habitat features such as tree species composition, vegetation cover, presence of water source, and soil characteristics are the parameter that helps to characterize the habitat of pangolins. Various associated environmental features such as canopy coverage and elevation are likely to be site-specific or habitat-specific for pangolins (Karawita et al., 2018).

\section{5 | CONCLUSION}

The study highlights the habitat use and major factors that affect the habitat choice of pangolins in Amritdharapani Community Forest of the Chitwan District. The study showed the preference of lower elevations, gentle slope, northwest aspect, moderate canopy coverage, reddish soil, acidic soils, area with less human disturbance, and area having easy access to water and food by the pangolins for digging burrows. Distance to settlement, distance to road, soil $\mathrm{pH}$, and canopy cover were found to affect the habitat choice of pangolins in the study area. This study can act as a baseline, which can assist in the conservation planning of the pangolin species at low lands of Nepal.

\section{ACKNOWLEDGMENTS}

We would like to thank National Trust for Nature ConservationBiodiversity Conservation Centre (NTNC-BCC) through USAID Hariyo Ban Program for providing financial and technical aid for this study and Amritdharapani Community Forest for field accommodation. Our special thanks to Ms. Saraswati Byanjankar, Ms. Shristi Shrestha, Mr. Bijay Bashyal, Mr. Deep Prasad Chaudhary/NTNCBCC, and Mr. Tikaram Tharu/NTNC-BCC for the field assistance. We are thankful to Prof. Dr. Chris Ray, Colorado University, for her guidance during the manuscript preparation. 


\section{CONFLICT OF INTEREST}

None declared.

\section{AUTHOR CONTRIBUTIONS}

Arati Shrestha: Conceptualization (lead); data curation (lead); funding acquisition (lead); investigation (lead); methodology (lead); project administration (lead); writing-original draft (lead); writing-review and editing (lead). Santosh Bhattarai: Conceptualization (equal); data curation (equal); funding acquisition (equal); methodology (equal); project administration (equal); supervision (supporting); writingoriginal draft (supporting); writing-review and editing (supporting). Binod Shrestha: Conceptualization (supporting); data curation (supporting); funding acquisition (supporting); methodology (supporting); project administration (supporting); writing-original draft (supporting); writing-review and editing (supporting). Narayan Prasad Koju: Conceptualization (equal); data curation (equal); formal analysis (equal); funding acquisition (supporting); investigation (equal); methodology (equal); project administration (equal); supervision (lead); writing-original draft (supporting); writing-review and editing (equal).

\section{DATA AVAILABILITY STATEMENT}

The data associated with this manuscript are available at: https:// datadryad.org/stash/share/zD-q70_8acle035PggIZzY5PKVwcazC1 qi4gDYU7hUU

\section{ORCID}

Arati Shrestha (iD https://orcid.org/0000-0001-5180-8526 Santosh Bhattarai iD https://orcid.org/0000-0001-7615-1954 Binod Shrestha (iD https://orcid.org/0000-0003-2781-7742 Narayan Prasad Koju iD https://orcid.org/0000-0002-4303-0520

\section{REFERENCES}

Acharya, P. M. (2001). Status and distribution of pangolin in the Nagarjun forest in Central Nepal (Abs). Workshop on Asian Pangolin.

Acharya, S., Sharma, H. P., Bhattarai, R., Poudyal, B., Sharma, S., \& Updhaya, S. (2021). Distribution and habitat preferences of the Chinese Pangolin Manis Pentadactyla (Mammalia: Manidae) in the Mid-Hills of Nepal. Journal of Threatened Taxa, 13(8), 18959-18966. https://doi.org/10.11609/jott.3952.13.8.18959-18966

Akrim, F., Mahmood, T., Hussain, R., Qasim, S., \& Zangi, I. (2017). Distribution pattern, population estimation and threats to the Indian Pangolin Manis crassicaudata (Mammalia: Pholidota: Manidae) in and around Pir Lasura National Park, Azad Jammu \& Kashmir, Pakistan. Journal of Threatened Taxa, 9(3), 9920-9927. https://doi.org/10.11609/jott.2914.9.3.9920-9927

Aryal, C. M., \& Poudel, N. (2018). Habitat Features associated with Chinese Pangolin distribution in Nagarjun and Ranibari Forests, Kathmandu, Nepal. Goldengate Journal of Science \& Technology, 4, 62-68.

Baral, H. S., \& Shah, K. B. (2008). Wild mammals of Nepal (pp. 94). Himalayan Nature.

Bhandari, N., \& Chalise, M. K. (2014). Habitat and distribution of Chinese Pangolin (Manis pentadactyla Linnaeus, 1758) in Forest of Shivapuri Nagarjun National Park, Nepal. Nepalese Journal of Zoology, 2(1), 18-25.

Bista, D., Shrestha, S., Sherpa, P., Thapa, G. J., Kokh, M., Lama, S. T., Khanal, K., Thapa, A., \& Jnawali, S. R. (2017). Distribution and habitat use of red panda in the Chitwan-Annapurna Landscape of Nepal. PLoS One, 12(10), e0178797. https://doi.org/10.1371/journ al.pone. 0178797

Challender, D., Wu, S., Kaspal, P., Khatiwada, A., Ghose, A., ChingMin Sun, N., Mohapatra, R. K., \& Laxmi Suwal, T. (2019). Manis pentadactyla. The IUCN Red List of Threatened Species 2019:e. T12764A168392151. Accessed 01 April 2020.

CITES (2016). Appendices I, II and III. Retrieved from http://www.cites. org/eng/app/appendices.php. Accessed 01 April 2020

Dhakal, S. (2016). Distribution and Conservation Status of Chinese Pangolin (Manis pentadactyla) in Palungtar Municipality of Gorkha District, Western Nepal, Kathmandu Forestry College, Tribhuvan University, Kathmandu.

Dhital, S., Paudel, S. M., Thapa, S., Bleisch, W. V., Shrestha, A., \& Koju, N. P. (2020). Distribution of Chinese pangolin (Manis pentadactyla) in Nagarjun forest of Shivapuri Nagarjun National Park, Nepal. Nepalese Journal of Zoology, 4(1), 1-7. https://doi.org/10.3126/njz. v4i1.30667

DNPWC \& DoF (2018). Pangolin Conservation Action Plan for Nepal (20182022). Department of National Parks and Wildlife Conservation and Department of Forests.

Dorji, D., Jambay, Ju Lian Chong, \& Dorji, T. (2020). Habitat preference and current distribution of Chinese Pangolin (Manis Pentadactyla L. 1758) in Dorokha Dungkhag, Samtse, Southern Bhutan. Journal of Threatened Taxa, 12(11), 16424-16433. https://doi.org/10.11609/ jott.5839.12.11.16424-16433

Gathorne-Hardy, F., Syaukani, \& Eggleton, P. (2001). The effects of altitude and rainfall on the composition of the termites (Isoptera) of the Leuser Ecosystem (Sumatra, Indonesia). Journal of Tropical Ecology, 17, 79-393. https://doi.org/10.1017/S026646740 1001262

Gurung, J. B. (1996). A pangolin survey in royal Nagarjung forest in Kathmandu, Nepal. Tiger Paper, 23(2), 29-32.

Heath, M. E., \& Vanderlip, S. L. (1988). Biology, husbandry and veterinary care of captive Chinese pangolins (Manis pentadactyla). Zoo Biology, 5(4), 387-390.

Jackson, J. E. (1991). A user's guide to principal components. A WileyInterscience Publication.

Jnawali, S. R., Baral, H. S., Lee, S., Acharya, K. P., Upadhyay, G. P., Pandey, M., Shrestha, R., Joshi, D., Laminchhane, B. R., Griffiths, J., Khatiwada, A. P., Subedi, N., \& Amin, R. (2011). The status of Nepal mammals: The national red list series. Department of National Parks and Wildlife Conservation.

Karawita, H., Perera, P., Gunawardane, P., \& Dayawansa, N. (2018). Habitat preference and den characterization of Indian Pangolin (Manis crassicaudata) in a tropical lowland forested landscape of southwest Sri Lanka. PLoS One, 13(11), e0206082. https://doi. org/10.1371/journal.pone.0206082

Kaspal, P. (2009). Saving the Pangolins: Ethno zoology and Pangolin conservation awareness in Human dominated Landscapes. The Rufford Small Grants Foundation. Retrieved from https://www.ruffo rd.org/files/40.09.08\%20Preliminary\%20Report_0.pdf (accessed 01 April, 2020)

Katuwal, H. B., Parajuli, K., Baral, S., \& Thapa, S. (2013). Pangolin Trade, Status, Ethnicity and its Conservation in Nepal. Report to Ensemble Foundation, Fresno Chaffee Zoo, WWF Nepal and Small Mammals Conservation and Research Foundation, Kathmandu, Nepal.

Katuwal, H. B., Sharma, H. P., \& Parajuli, K. (2017). Anthropogenic impacts on the occurrence of the critically endangered Chinese pangolin (Manis pentadactyla) in Nepal. Journal of Mammalogy, 98(6), 1667-1673. https://doi.org/10.1093/jmammal/gyx114

Kingdon, J. S., Hoffmann, M., \& Hoyt, R. (2013). Smutsia gigantea Giant Ground Pangolin. In L. S. Kingdon \& M. Hoffmann (Eds.). The mammals of Africa. Carnivores, pangolins, equids, rhinoceros (Vol. 5, pp. 396-399). Bloomsbury Publishing. 
Lamichhane, U., \& Pokhrel, B. (2019). Understanding the distribution, conservation and threats to pangolin (Manis spp.). Grassroots Journal of Natural Resources, 2, 37-44. https://doi.org/10.33002/ nr2581.6853.02124

Lemmon, P. E. (1956). A spherical densiometer for estimating Forest Overstory Density. Forest Science, 2, 314-320.

Li, Y., Dong, Z. Y., Pan, D. Z., Pan, C. H., \& Chen, L. H. (2017). Effect of termite on soil $\mathrm{pH}$ and its application for termite control in Zhejiang Province, China. Sociobiology, 64(3), 317-326. https://doi. org/10.13102/sociobiology.v64i3.1674

Mahmood, T., Akrim, F., Irshad, N., Hussain, R., Fatima, H., Andleeb, S., \& Aihetasham, A. (2019). Distribution and illegal killing of the Endangered Indian pangolin Manis crassicaudata on the Potohar Plateau, Pakistan. Oryx, 53(1), 159-164. https://doi.org/10.1017/ S0030605317000023

Mahmood, T., Challender, D., Khatiwada, A., Andleeb, S., Perera, P., Trageser, S., Ghose, A., \& Mohapatra, R. (2019). Manis crassicaudata. The IUCN Red List of Threatened Species 2019: e.T12761A123583998. https://doi.org/10.2305/IUCN.UK.2019-3.RLTS.T12761A123 583998.en. Accessed 01 April 2020

Mahmood, T., Irshad, N., \& Hussain, R. (2014). Habitat preferences and population estimates of Indian pangolin (Manis crassicaudata) in district Chakwal of Potohar Plateau, Pakistan. Russian Journal of Ecology, 45(1), 70-75. https://doi.org/10.1134/S106741361 4010081

Marler, P. N. (2016). Camera trapping the Palawan Pangolin Manis culionensis (Mammalia: Pholidota: Manidae) in the wild. Journal of Threatened Taxa, 8(12), 9443-9448. https://doi.org/10.11609/ jott.2867.8.12.9443-9448

Maurice, M. E., Ebong, E. L., Fuashi, N. A., Godwill, I. I., \& Zeh, A. F. (2019). The ecological impact on the distribution of pangolins in Deng-Deng National Park, Eastern Region, Cameroon. Annals of Ecology and Environmental Science, 3(1), 23-32. https://doi.org/10.17352/gje

NPWCA (1973). Retrieved from http://www.lawcommission.gov.np/en/ archives/13289. Accessed on April 17, 2020

Pabasara, M., Perera, P., \& Dayawansa, N. (2015). A preliminary investigation of the habitat selection of Indian pangolin (Manis crassicaudata) in a tropical lowland forest in South-west Sri Lanka. In Proceedings of 20th International Forestry and Environment Symposium, 2015, Sri Lanka.

Poudel, J. (2014). Socio-Cultural Impact in Tourism: A Case Study of Sauraha, Nepal. Journal of Advanced Academic Research, 1(2), 47-55. https://doi.org/10.3126/jaar.v1i2.16588

Rai, A., Sharma, S., Shrestha, S., Bashyal, A., Shrestha, S., \& Khanal, S. N. (2019). Habitat Analysis and Distribution of Chinese Pangolin in Community Forests of Dolakha District, Nepal. In Conference Proceedings of International Conference on Natural Resources, Agriculture and Society in Changing Climate (NRACC)-2019Kathmandu, 17-19 August, 2019.

Sharma, S., Sharma, H. P., Chaulagain, C., Katuwal, H. B., \& Belant, J. L. (2020). Estimating occupancy of Chinese pangolin (Manis pentadactyla) in a protected and non-protected area of Nepal. Ecology and Evolution, 00, 01-11. https://doi.org/10.1002/ece3.6198

Shenoy, K., Varma, S., \& Devi Prasad, K. V. (2006). Factors determining habitat choice of the smooth-coated otter, Lutra perspicillata in a South Indian river system. Current Science, 91, 637-643.

Suwal, T. L. (2011). Status, distribution, behavior and conservation of pangolins in private and community forests of Balthali in Kavre, Nepal. M.Sc. Thesis. Central Department of Zoology. Kirtipur, Kathmandu.

Suwal, T. L., Thapa, A., Gurung, S., Aryal, P. C., Basnet, H., Basnet, K., Shah, K. B., Thapa, S., Koirala, S., Dahal, S., Katuwal, H. B., Sharma, N., Jnawali, S. R., Khanal, K., Dhakal, M., Acharya, K. P., Ingram, D. J., \& Pei, K. J. C. (2020). Predicting the potential distribution and habitat variables associated with pangolin in Nepal. Global Ecology and Conservation, 23, e01049. https://doi.org/10.1016/j. gecco.2020.e-01049

Swart, J. M., Richardson, P. R. K., \& Ferguson, W. H. (1999). Ecological factors affecting the feeding behaviour of pangolins (Manis temminckii). Journal of Zoology, 247, 281-292. https://doi.org/10.1111/ j.1469-7998.1999.tb00992.x

Thapa, P., Khatiwada, A. P., Nepali, S. C., \& Paudel, S. (2014). Distribution and Conservation Status of Chinese pangolin (Manis pentadactyla) in Nangkholyang VDC, Taplejung, Eastern Nepal. American Journal of Zoological Research, 2(1), 16-21. https://doi.org/10.12691/ ajzr-2-1-3

Waseem, M., Khan, B., Mahmood, T., Hussain, H. S., Aziz, R., Akrim, F., Ahmad, T., Nazir, R., Ali, M. W., \& Awan, M. N. (2020). Occupancy, habitat suitability and habitat preference of endangered Indian pangolin (Manis crassicaudata) in Potohar Plateau and Azad Jammu and Kashmir, Pakistan. Global Ecology and Conservation, 23, e01135. https://doi.org/10.1016/j.geco.2020.e01135

Wu, S. B., Liu, N. F., Ma, G. Z., Xu, Z. R., \& Chen, H. (2003). Habitat selection by Chinese pangolin (Manis pentadactyla) in winter in Dawuling Natural Reserve. Mammalia, 67(4), 493-502. https://doi. org/10.1515/mamm-2003-0403

Wu, S. B., Ma, G. Z., Tang, M., Chen, H., Xu, Z., \& Liu, N. F. (2004). A preliminary study on burrow ecology of Manis pentadactyla. Chinese Journal, 15(3), 401-407.

Zhang, M., Gouveia, A., Qin, T., Quan, R., \& Nijman, V. (2017). Illegal pangolin trade in northernmost Myanmar and its links to India and China. Global Ecology and Conservation, 10, 23-31. https://doi. org/10.1016/j.gecco.2017.01.006

How to cite this article: Shrestha, A., Bhattarai, S., Shrestha, B., $\&$ Koju, N. P. (2021). Factors influencing the habitat choice of pangolins (Manis spp.) in low land of Nepal. Ecology and Evolution, 11, 14689-14696. https://doi.org/10.1002/ ece3.8156 